\title{
Article \\ Ultrasensitive Leaky Surface Acoustic Wave Immunosensor for Real-Time Detection of Alpha-Fetoprotein in Biological Fluids
}

\author{
Sana Rauf ${ }^{1}$, Hafiz Imran Ahmad Qazi ${ }^{2}$, Jingting Luo ${ }^{1, *}$, Chen Fu ${ }^{1}$, Ran Tao ${ }^{1}$, Sajid Rauf ${ }^{3}$, Lei Yang ${ }^{1}$, \\ Honglang $\mathrm{Li}^{4,5,6}$ and Yongqing $\mathrm{Fu}^{7}$ \\ 1 Key Laboratory of Optoelectronic Devices and Systems of Education Ministry and Guangdong Province, \\ College of Physics and Optoelectronic Engineering, Shenzhen University, Shenzhen 518060, China; \\ sanichms@gmail.com (S.R.); chenfu@szu.edu.cn (C.F.); ran.tao@szu.edu.cn (R.T.); \\ yangleigas@foxmail.com (L.Y.) \\ 2 SZU-CASIPP Joint Laboratory for Applied Plasma, College of Physics and Optoelectronic Engineering, \\ Shenzhen University, Shenzhen 518060, China; emranphy@gmail.com \\ 3 College of Electronics and Information Engineering, Shenzhen University, Shenzhen 518086, China; \\ sajidrauf.physics@gmail.com \\ 4 National Center for Nanoscience and Technology, Beijing 100190, China; lhl@nanoctr.cn \\ 5 GBA Research Innovation Institute for Nanotechnology, Guangzhou 510700, China \\ 6 Guangdong Guangnaxin Technology Co., Ltd., Guangzhou 510700, China \\ 7 Faculty of Engineering and Environment, Northumbria University, Newcastle upon Tyne NE1 8ST, UK; \\ Richard.fu@northumbria.ac.uk \\ * Correspondence: luojt@szu.edu.cn
}

\section{check for} updates

Citation: Rauf, S.; Qazi, H.I.A.; Luo, J.; Fu, C.; Tao, R.; Rauf, S.; Yang, L.; Li, H.; Fu, Y. Ultrasensitive Leaky Surface Acoustic Wave

Immunosensor for Real-Time Detection of Alpha-Fetoprotein in Biological Fluids. Chemosensors 2021, 9, 311. https://doi.org/10.3390/ chemosensors 9110311

Academic Editor: Nicole

Jaffrezic-Renault

Received: 14 October 2021

Accepted: 31 October 2021

Published: 4 November 2021

Publisher's Note: MDPI stays neutral with regard to jurisdictional claims in published maps and institutional affiliations.

Copyright: (c) 2021 by the authors. Licensee MDPI, Basel, Switzerland. This article is an open access article distributed under the terms and conditions of the Creative Commons Attribution (CC BY) license (https:// creativecommons.org/licenses/by/ $4.0 /)$.

\begin{abstract}
We propose an ultrasensitive leaky surface acoustic wave (LSAW) immunosensor based on molybdenum disulfide @ cuprous oxide-gold $\left(\mathrm{MoS}_{2} @ \mathrm{Cu}_{2} \mathrm{O}-\mathrm{Au}\right)$ nanoparticles and subsequent gold staining for the detection of alpha-fetoprotein (AFP). $\mathrm{MoS}_{2} @ \mathrm{Cu}_{2} \mathrm{O}-\mathrm{Au}$ nanoparticles, with their large specific surface area and good biocompatibility, not only capture the secondary antibodies $\left(\mathrm{Ab}_{2}\right)$ but also amplify the mass loading effect of the acoustic wave sensor in the detection of AFP. The immunosensor signals are further amplified upon injection of gold staining solution. The developed immunosensor achieved a low detection limit of 5.5 and $25.0 \mathrm{pg} / \mathrm{mL}$ with and without gold staining, respectively. The immunosensor demonstrated its efficiency for the quantitative detection of AFP in complex biological fluids, including human serum and saliva samples, with excellent selectivity and long-term stability, showing great potential for the quantification of AFP in clinical diagnosis.
\end{abstract}

Keywords: leaky surface acoustic wave (LSAW); immunosensor; AFP; $\mathrm{MoS}_{2} @ \mathrm{Cu}_{2} \mathrm{O}-\mathrm{Au}$; gold staining

\section{Introduction}

Cancer poses a serious threat to human health worldwide, and its early diagnosis has the potential to reduce mortality rates. The detection of tumor markers is an effective approach for the early diagnosis of cancer [1]. Alpha-fetoprotein (AFP), an embryo-specific glycoprotein, is a widely accepted biomarker for fetal defects and tumor progression. The level of AFP in serum of healthy humans is generally below $25 \mathrm{ng} / \mathrm{mL}$, while its concentration increases up to $500 \mathrm{ng} / \mathrm{mL}$ in some diseases, such as the germ cell tumor, hepatocellular carcinoma (HCC), and yolk sac tumor [2]. The concentration of serum AFP is considered as a gold standard for the diagnosis of HCC in liver cancer patients. However, the use of saliva for the detection of tumor markers is noninvasive and more acceptable for screening than the serum assay. Accordingly, ultrasensitive detection of AFP in body fluids is crucial for the early diagnosis of cancer.

Numerous detection methods, including fluorescence, electrochemical, colorimetric, and enzyme-linked immunosorbent assays, have been established for the quantification of AFP [3-6]. However, several techniques have major drawbacks, such as long analysis time, 
low sensitivity, high background, and high cost. Hence, a simple, real-time, and highly sensitive detection platform for the quantification of AFP is in high demand.

Surface acoustic wave (SAW) sensors are currently gaining increasing popularity for the detection of tumor markers in body fluids for the early diagnosis of cancer $[7,8]$. SAW sensors have numerous advantages, including simple operation, low cost, rapid response, high sensitivity, and real-time detection capabilities [9]. These features grant SAW sensors advantages in detecting a large variety of analytes, such as biological warfare agents, small molecules, heavy metals, uric acid, and cancer cells [10-14].

SAW devices are categorized into three different types based on the surface waves exploited, including Rayleigh wave (R-SAW) devices, Lamb wave (LSAW) devices, and Shear horizontal (SH-SAW) devices [15-17]. Both Rayleigh and Lamb waves are significantly dampened in liquid media and thus overwhelmingly used for gas sensing. In contrast, SH-SAWs are less influenced by the liquid environment owing to in-plane mechanical vibration and are thus mostly used for biosensing applications.

SH-SAW devices fall primarily into two major types. The Love wave surface acoustic wave (LW-SAW) sensors have a two-layered structure, where a guiding layer is deposited on top of a piezoelectric material. The leaky surface acoustic wave (LSAW) biosensors do not require an additional guiding layer and are thus easier to fabricate. LSAW sensors employ a specific cutting plane of piezoelectric crystals $\left(36^{\circ} \mathrm{YX}\right.$-lithium tantalate $\left.\left(\mathrm{LiTaO}_{3}\right)\right)$ to generate the LSAW mode. Unlike conventional Rayleigh waves, LSAW sensors have a large electromechanical coupling factor, higher dielectric constant values, and high sensitivity $[18,19]$.

Recently, Chang et al., proposed an LSAW immunosensor for the detection of cyclosporine A (CsA) in whole-blood samples [20]. The same group later developed a label-free and highly sensitive LSAW aptasensor for the detection of tumor markers [21]. $\mathrm{Xu}$ et al. proposed an LSAW immunosensor for the detection of single-nucleotide polymorphisms based on enzymatic signal amplification [22]. Similarly, the LSAW biosensor platform has been successfully used for the detection of DNA and the human papillomavirus [23,24]. However, no studies to date have reported the ultrasensitive detection of AFP using LSAW sensors.

SAW sensors are $4-5$ times more sensitive than other piezoelectric sensors, such as quartz crystal microbalances; however, their sensitivity must be further enhanced for the ultrasensitive detection of cancer biomarkers [25]. Signal amplification associated with the use of nanomaterial labeling can provide an ultralow limit of detection.

To date, a wide variety of signal amplification systems have been reported for immunosensors, including strategies based on metal oxides, enzymes, noble metal nanoparticles, and nanocomposite materials [26-28]. Among the metal oxides, $\mathrm{Cu}_{2} \mathrm{O}$ has attracted significant attention as a promising candidate for the fabrication of biosensors owing to its environmental compatibility, low cost, and large surface area [29]. However, sole $\mathrm{Cu}_{2} \mathrm{O}$ nanocrystals are prone to agglomeration and exhibit poor dispersion. The dispersion and stability of $\mathrm{Cu}_{2} \mathrm{O}$ nanocrystals can be improved by combining them with molybdenum disulfide $\left(\mathrm{MoS}_{2}\right)$ nanoparticles. $\mathrm{MoS}_{2}$ nanoflowers have been largely used in the construction of biosensors owing to their large surface area, good conductivity, and outstanding charge-transport ability [30]. To combine the secondary antibody with $\mathrm{Cu}_{2} \mathrm{O} @ \mathrm{MoS}_{2}$ nanoparticles and enhance biocompatibility, the combination of AuNPs is a promising strategy [31,32].

Gold staining is a widely used robust signal amplification strategy for the highly sensitive detection of biomarkers [33,34]. In this process, AuNPs act as a catalyst to reduce the gold (III) ions to metallic gold in the presence of reducing agents, such as hydroxylamine hydrochloride. This reaction leads to the deposition of gold on the AuNPs as nucleation sites, increasing their mass and size, and thus resulting in remarkable signal amplification of the immunoassay.

Herein, an ultrasensitive, sandwich-type LSAW immunosensor based on $\mathrm{MoS}_{2} @ \mathrm{Cu}_{2} \mathrm{O}-$ $\mathrm{Au}$ nanoparticles and subsequent gold staining as a signal amplification strategy was 
proposed for the detection of AFP, as illustrated in Figure 1. Owing to their good stability, great biocompatibility, and large specific surface area, $\mathrm{MoS}_{2} @ \mathrm{Cu}_{2} \mathrm{O}-\mathrm{Au}$ nanoparticles not only enhance the number of captured antibodies but also increase the mass loading on the sensor surface, resulting in high sensitivity. The markedly amplified sensitivity was achieved further by injecting the gold staining solution. The immunoassay was conducted with varying concentrations of AFP from 0.01 to $50 \mathrm{ng} / \mathrm{mL}$ and achieved an ultralow limit of detection (LOD) of 5.5 and $25 \mathrm{pg} / \mathrm{mL}$ with and without gold staining, respectively. The real-sample detection capabilities of the presented biosensor were evaluated by detecting AFP in human serum and saliva samples with satisfactory results. Salivary AFP detection is a promising strategy for the detection of HCC with saliva as the diagnostic fluid alternative to the serum assay. In addition, the immunosensor exhibited acceptable selectivity and excellent long-term stability, which has promising applications for clinical diagnosis.

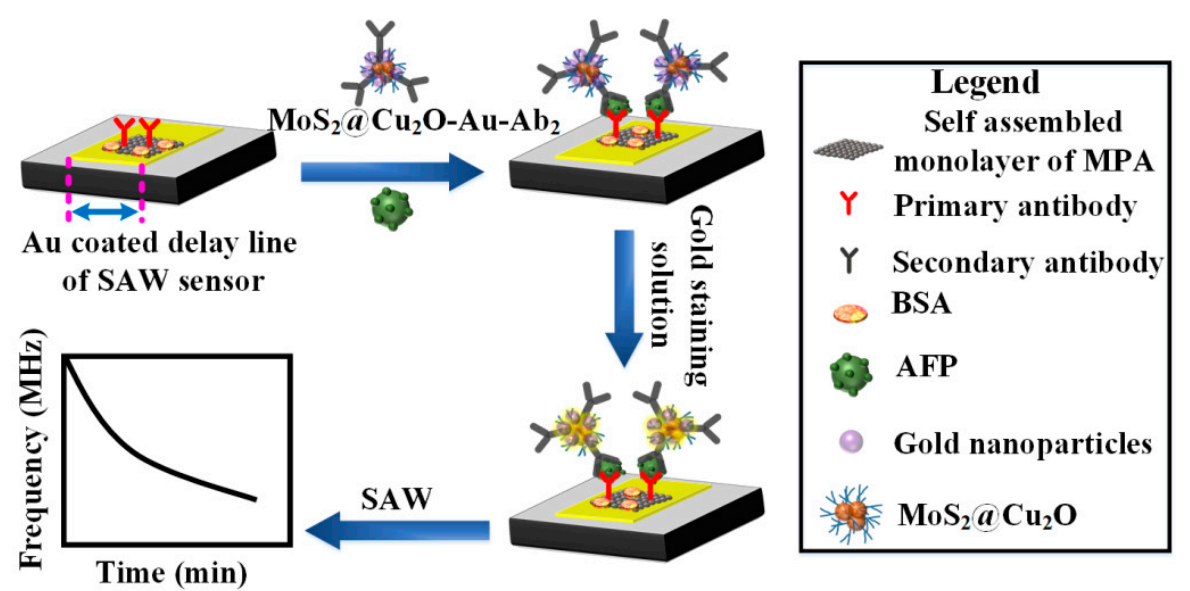

Figure 1. Schematic representation of sandwich-type SAW immunosensor for detection of AFP.

\section{Materials and Methods}

\subsection{Reagents}

Mercaptoacetic acid, N-hydroxy succinimide (NHS), ethyl dimethyl aminopropyl carbodiimide (EDC), tetrachloroauric acid $\left(\mathrm{HAuCl}_{4}\right)$, carcinoembryonic antigen (CEA), bovine serum albumin (BSA), tryptophan, and all the other reagents of analytical grade were purchased from Sigma-Aldrich (Shanghai, China). Prostate-specific antigen (PSA) was purchased from RayBiotech, Inc (China). Alpha-fetoprotein (AFP) was purchased from Novus Biologicals (China). The primary anti-AFP antibody $\left(\mathrm{Ab}_{1}\right)$, FITC-labeled primary anti-AFP antibody $\left(\mathrm{Ab}_{1}\right.$-FITC), and the secondary anti-AFP antibody $\left(\mathrm{Ab}_{2}\right)$ were purchased from Abcam, USA. Human serum was obtained from Second People's Hospital, Shenzhen, China. Human saliva samples were collected from a healthy donor. Phosphate-buffered saline (PBS, pH 7.4) was synthesized using $\mathrm{Na}_{2} \mathrm{HPO}_{4}$ and $\mathrm{KH}_{2} \mathrm{PO}_{4}$. Deionized (DI) water was used in all experiments.

\subsection{Preparation of $\mathrm{MoS}_{2} @ \mathrm{Cu} u_{2} \mathrm{O}-\mathrm{Au}-\mathrm{Ab} 2$ Conjugate}

The $\mathrm{MoS}_{2} @ \mathrm{Cu}_{2} \mathrm{O}$ nanohybrid was prepared according to the procedures reported in a previous study [30]. In brief, $26 \mathrm{mg}$ of ammonium tetrathiomolybdate $\left(\left(\mathrm{NH}_{4}\right)_{2} \mathrm{MoS}_{4}\right)$ and $80 \mathrm{mg}$ of copper nitrate trihydrate $\left(\mathrm{Cu}\left(\mathrm{NO}_{3}\right)_{2} \cdot 3 \mathrm{H}_{2} \mathrm{O}\right)$, each in $20 \mathrm{~mL}$ of DI water, were mixed after sonication for $8 \mathrm{~min}$, separately. Subsequently, $200 \mu \mathrm{L}$ of hydrazine hydrate $\left(\mathrm{N}_{2} \mathrm{H}_{4} \bullet \mathrm{H}_{2} \mathrm{O}\right)$ was added dropwise into the aqueous mixture and sonicated again for $25 \mathrm{~min}$. The aqueous mixture was kept at $200{ }^{\circ} \mathrm{C}$ for $10 \mathrm{~h}$ in a Teflon-lined autoclave in an oven. The obtained product was rinsed in succession with water and ethanol five times. Finally, the product was dispersed into $3.0 \mathrm{~mL}$ of water and frozen-dried to obtain solid powder.

For comparison, $\mathrm{Cu}_{2} \mathrm{O}$ nanocrystals were synthesized similarly to the preparation of $\mathrm{MoS}_{2} @ \mathrm{Cu}_{2} \mathrm{O}$ nanohybrid, but with the addition of $150 \mu \mathrm{L} \mathrm{N}_{2} \mathrm{H}_{4} \bullet \mathrm{H}_{2} \mathrm{O}$ and without added $\left(\mathrm{NH}_{4}\right)_{2} \mathrm{MoS}_{4}$. Furthermore, $\mathrm{MoS}_{2}$ nanoflowers were also synthesized in a similar 
manner as in the preparation of the $\mathrm{MoS}_{2} @ \mathrm{Cu}_{2} \mathrm{O}$ nanohybrid, but with the addition of $50 \mu \mathrm{L} \mathrm{N}_{2} \mathrm{H}_{4} \bullet \mathrm{H}_{2} \mathrm{O}$ and without $\mathrm{Cu}\left(\mathrm{NO}_{3}\right)_{2} \bullet 3 \mathrm{H}_{2} \mathrm{O}$.

The preparation of gold nanoparticles was based on previous reports [35]. Briefly, $\mathrm{HAuCl}_{4}$ aqueous solution $(0.01 \%, 100 \mathrm{~mL})$ was heated to boil with vigorous stirring. Afterwards, trisodium citrate solution $(1 \%, 2.5 \mathrm{~mL})$ was added into the boiling $\mathrm{HAuCl}_{4}$ solution, resulting in a color change from light yellow to deep red. After the color change, heating was continued for another $15 \mathrm{~min}$. The resultant solution was allowed to cool to ambient temperature and stored at $4{ }^{\circ} \mathrm{C}$ for further use.

In the following step, $10 \mathrm{mg}$ synthesized $\mathrm{MoS}_{2} @ \mathrm{Cu}_{2} \mathrm{O}$ powder was dispersed in $10 \mathrm{~mL}$ of freshly prepared AuNPs solution under constant stirring for $24 \mathrm{~h}$. The resultant product was rinsed with DI water and ethanol to remove excess AuNPs. Finally, the sediments were dried in a vacuum oven and referred to as $\mathrm{MoS}_{2} @ \mathrm{Cu}_{2} \mathrm{O}-\mathrm{Au}$. $\mathrm{MoS}_{2} @ \mathrm{Cu}_{2} \mathrm{O}-\mathrm{Au}$ nanoparticles were characterized by scanning electron microscopy (SEM, Zeiss EVO-MA) and transmission electron microscopy (TEM, Titan 3 Themis G2, ThermoFisher Scientific). The elemental mapping for SEM images was carried out by energy-dispersive X-ray spectroscopy (EDS).

Four milligrams of $\mathrm{MoS}_{2} @ \mathrm{Cu}_{2} \mathrm{O}-\mathrm{Au}$ conjugate was ultrasonically dispersed in $1.0 \mathrm{~mL}$ ultrapure water. Subsequently, $20 \mu \mathrm{g} / \mathrm{mL} \mathrm{Ab} 2(1 \mathrm{~mL})$ was added in solution dropwise and shaken at $4{ }^{\circ} \mathrm{C}$ for $12 \mathrm{~h}$. The mixture was centrifuged and rinsed with DI water to remove unbound $\mathrm{Ab}_{2}$. Then, the precipitates were redispersed in $1 \mathrm{~mL}$ DI water and stored at $4{ }^{\circ} \mathrm{C}$.

\subsection{Fabrication of SAW Device}

The SAW devices were fabricated on a single-side, polished, $36^{\circ}$-rotated Y-cut and $X$-propagation $\mathrm{LiTaO}_{3}$ wafers. The SAW sensors were designed at a center frequency of $175 \mathrm{MHz}$. The input and output interdigital transducer (IDT) of each sensor contained 36 finger pairs with an electrode width and wavelength of 6 and $24 \mu \mathrm{m}$, respectively. First, the wafers were rinsed sequentially with acetone, isopropyl alcohol, followed by DI water, and dried with nitrogen gas. The IDT patterns were fabricated as follows. A negative photoresist (sunlift1303) was spin-coated on the piezoelectric wafer after solvent cleaning. After prebaking $\left(65^{\circ} \mathrm{C} / 30 \mathrm{~s}\right.$ and $\left.95^{\circ} \mathrm{C} / 90 \mathrm{~s}\right)$, the coated wafer was exposed to a UV light source for $2.1 \mathrm{~s}$, followed by another baking round $\left(65^{\circ} \mathrm{C} / 20 \mathrm{~s}\right.$ and $\left.95^{\circ} \mathrm{C} / 20 \mathrm{~s}\right)$. Finally, the wafer was treated with the developer solution for $25 \mathrm{~s}$, followed by washing with acetone.

The delay line area (space between two IDTs) with dimensions of $9.2 \mathrm{~mm} \times 7.2 \mathrm{~mm}$ was used for the immunoreaction. The Ti/Au $(20 / 50 \mathrm{~nm})$ thin film was deposited by electron beam physical evaporation on the delay line of SAW devices.

\subsection{Immobilization of $A b_{1}$ on Delay Line of $S A W$}

First, the Au-coated delay line area of the SAW sensor was cleaned with Piranha solution $\left(30 \% \mathrm{H}_{2} \mathrm{O}_{2}\right.$ : concentrated $\left.\mathrm{H}_{2} \mathrm{SO}_{4}=1: 3\right)$ for $5 \mathrm{~min}$. Then, the sensor was rinsed with DI water and ethanol, followed by drying with nitrogen gas. The same cleaning steps were used after each chemical treatment. Afterwards, the delay line was soaked in mercaptoacetic acid $(50 \mathrm{mM})$ for $16 \mathrm{~h}$ and rinsed with ethanol and DI water to remove the excess. In the following step, the delay line was treated with a 1:1 mixture solution of NHS (100 mM) and EDC ( $400 \mathrm{mM})$ in pure methanol for $2 \mathrm{~h}$ to activate the surface. After solvent cleaning and drying, the delay line was incubated with $100 \mu \mathrm{g} / \mathrm{mL}$ of $\mathrm{Ab}_{1}$ at $4{ }^{\circ} \mathrm{C}$ overnight. Then, it was treated with 3\% BSA in PBS for $3 \mathrm{~h}$ to block nonspecific adsorption. Finally, the delay line of the SAW sensor was washed with PBS, followed by drying with nitrogen gas. The immobilization of $\mathrm{Ab}_{1}$ on delay line of $\mathrm{SAW}$ sensor was confirmed using contact angle measurement system (CAG100 Contact Angle Goniometer, Beijing United Test Co., Ltd., Beijing, China), QCM frequency measurements (QCM-I, MicroVacuum Ltd., Budapest, Hungary), optical microscopy (CX40 Biological Optical Microscope, Ningbo Sunny Technology Co., Ltd., Zhejiang, China), and scanning electron microscopy (SEM, Zeiss EVOMA). 


\subsection{SAW-Based Sandwich Immunoassay}

The SAW measurement system comprises an injection pump, microfluidic chamber, network analyzer, and personal computer (PC), as shown in Figure 2. A specially designed microfluidic channel was fabricated to obtain automated quantitative sample injection. The injection pump (TS-1B syringe pump system, Longer Precision Pump Co., Ltd, Hebei, China) was used for injecting sample solutions on the surface of the SAW sensor placed in the microfluidic chamber, at a flow velocity of $25 \mu \mathrm{L} / \mathrm{min}$ (Figure 2).

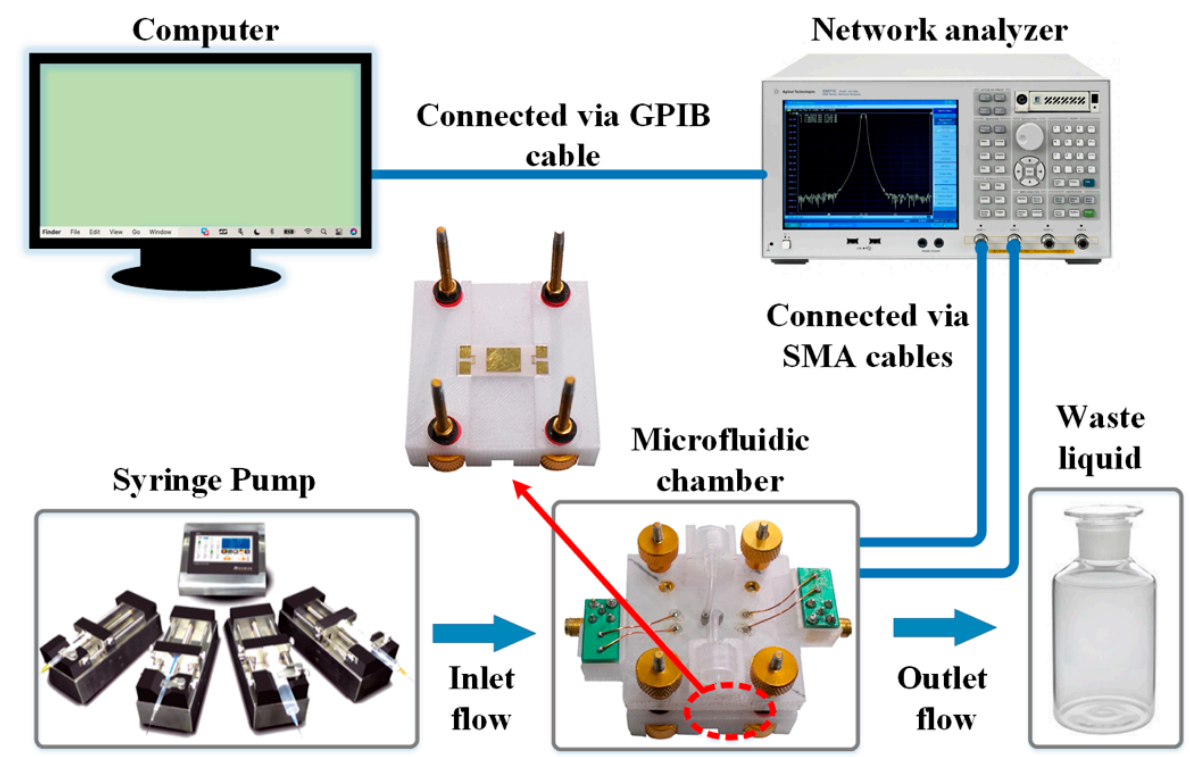

Figure 2. Experimental setup of SAW immunosensor, including a syringe pump, microfluidic chamber, network analyzer, and PC.

The immunoreaction was performed as follows. First, $10 \mathrm{mM}$ PBS was allowed to flow on the sensor surface placed in the microfluidic chamber at $25 \mu \mathrm{L} / \mathrm{min}$ to obtain a stable signal of the center frequency. Then, the AFP sample solution (in PBS) was incubated with $\mathrm{MoS}_{2} @ \mathrm{Cu}_{2} \mathrm{O}-\mathrm{Au}-\mathrm{Ab}_{2}$ conjugates, and this mixture was allowed to flow on the sensor surface at $5 \mu \mathrm{L} / \mathrm{min}$. After PBS washing, the gold staining solution comprising $20 \mathrm{mM}$ hydroxylamine hydrochloride and $10 \mathrm{mM}$ gold (III) chloride trihydrate was injected. Finally, the delay line was washed again with PBS until an equilibrate signal of center frequency was achieved.

AFP solutions of 0.01 to $50 \mathrm{ng} / \mathrm{mL}$ concentrations were tested using this immunoassay. Each concentration of AFP was tested in triplicate, and the shift in the center frequency for the immunoreaction was recorded as the mean \pm standard deviation (SD) to evaluate the repeatability. The center frequency change for each test was recorded using a network analyzer, Keysight Technologies, E5071C. Data were recorded in real time by a specific program based on LabVIEW software.

\section{Results and Discussion}

\subsection{Characterization of $\mathrm{MoS}_{2} @ \mathrm{Cu}_{2} \mathrm{O}-\mathrm{Au}$}

The morphology of $\mathrm{MoS}_{2} @ \mathrm{Cu}_{2} \mathrm{O}-\mathrm{Au}$ nanoparticles at various stages of synthesis was characterized by scanning electron microscopy (SEM). Figure 3A shows the SEM image of the as-synthesized $\mathrm{Cu}_{2} \mathrm{O}$ nanocrystals with an average size of $\sim 80-120 \mathrm{~nm}$. Similarly, the SEM and TEM images of as-synthesized $\mathrm{MoS}_{2}$ exhibited a flower-like morphology with a large surface area (Figure $3 \mathrm{~B}, \mathrm{E}$ ). Upon the addition of $\mathrm{Cu}_{2} \mathrm{O}$ nanocrystals to the solution during $\mathrm{MoS}_{2}$ nanoflower synthesis, $\mathrm{Cu}_{2} \mathrm{O}$ nanocrystals were dispersed with $\mathrm{MoS}_{2}$ nanoflowers, which results in the formation of coral-like $\mathrm{MoS}_{2} @ \mathrm{Cu}_{2} \mathrm{O}$ nanohybrids (Figure 3C). The uniform dispersion of the $\mathrm{MoS}_{2} @ \mathrm{Cu}_{2} \mathrm{O}$ nanohybrid was further confirmed by TEM (Figure 3G). When gold nanoparticles (AuNPs) were added to the $\mathrm{MoS}_{2} @ \mathrm{Cu}_{2} \mathrm{O}$ 
nanohybrid, the surface morphology changed significantly (Figure 3D,H). Numerous AuNPs were loaded on the $\mathrm{MoS}_{2} @ \mathrm{Cu}_{2} \mathrm{O}$ nanohybrid by vigorous shaking, as observed in the TEM image of $\mathrm{MoS}_{2} @ \mathrm{Cu}_{2} \mathrm{O}-\mathrm{Au}$ (Figure 3H). The diameter of AuNPs is $13 \mathrm{~nm}$, measured using the TEM image (Figure $3 \mathrm{~F}$ ).
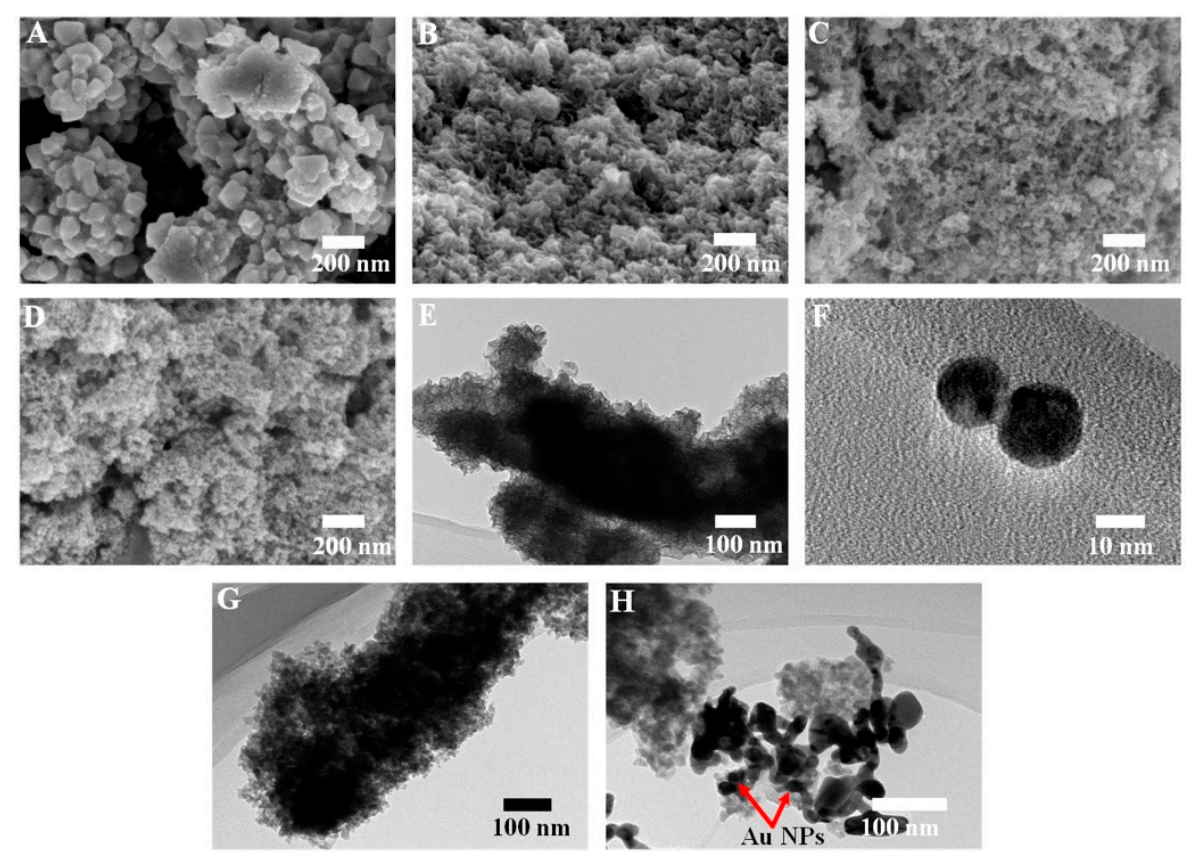

Figure 3. SEM images of $\mathrm{Cu}_{2} \mathrm{O}(\mathrm{A}), \mathrm{MoS}_{2}(\mathbf{B}), \mathrm{Cu}_{2} \mathrm{O} @ \mathrm{MoS}_{2}(\mathrm{C}), \mathrm{Cu}_{2} \mathrm{O} @ \mathrm{MoS}_{2}-\mathrm{Au}$ (D); TEM images of $\mathrm{MoS}_{2}(\mathbf{E}), \operatorname{AuNPs}(\mathbf{F}), \mathrm{Cu}_{2} \mathrm{O} @ \mathrm{MoS}_{2}(\mathbf{G})$, and $\mathrm{Cu}_{2} \mathrm{O} @ \mathrm{MoS}_{2}-\mathrm{Au}(\mathbf{H})$.

The elemental composition of $\mathrm{MoS}_{2} @ \mathrm{Cu}_{2} \mathrm{O}-\mathrm{Au}$ was characterized by SEM-EDS elemental mapping, as shown in Figure S1. From these images, the presence of $\mathrm{Au}, \mathrm{Mo}, \mathrm{O}$, $\mathrm{Cu}$, and $\mathrm{S}$ elements in this material is clearly observed, which is further verified by the energy-dispersive X-ray (EDX) spectra of $\mathrm{MoS}_{2} @ \mathrm{Cu}_{2} \mathrm{O}$-Au in Figure S2. The elemental mapping indicates successful synthesis of $\mathrm{MoS}_{2} @ \mathrm{Cu}_{2} \mathrm{O}-\mathrm{Au}$ nanoparticles.

\subsection{Preparation and Characterization of Self-Assembled Monolayer (SAM)}

The scheme of a sandwich-type SAW immunosensor for the detection of AFP is presented in Figure 1. First, an oriented mercaptoacetic acid monolayer can be directly formed on the Au-coated SAW surface via strong Au-S bonds, with the tail carboxylic groups oriented at the interface [36]. Upon activation with EDC and NHS, carboxylic groups were replaced with ester groups. Finally, ester groups were replaced by amine groups of primary antibodies $\left(\mathrm{Ab}_{1}\right)$, which resulted in the immobilization of $\mathrm{Ab}_{1}$ on the SAW surface as a SAM layer. The immobilization of $A b_{1}$ on the sensor surface was characterized by QCM frequency measurements based on previous reports [28]. Figure 4A shows the typical sensorgram for each step of QCM electrode fabrication. The bare electrode (Au coated) was adopted as a reference (Curve a). Curve b shows the decrease in the QCM frequency due to the binding of MPA on the sensor surface, resulting from its reaction with the gold-coated electrode. The frequency decreased further as the electrode was incubated with NHS/EDC, showing coupling of the molecules on the sensor surface (Curve c). A significant frequency shift was observed when $\mathrm{Ab}_{1}$ was injected on the electrode surface, indicating mass loading on the sensor surface (Curve $d$ ). These results confirmed the immobilization of $A b_{1}$ onto the electrode surface. 

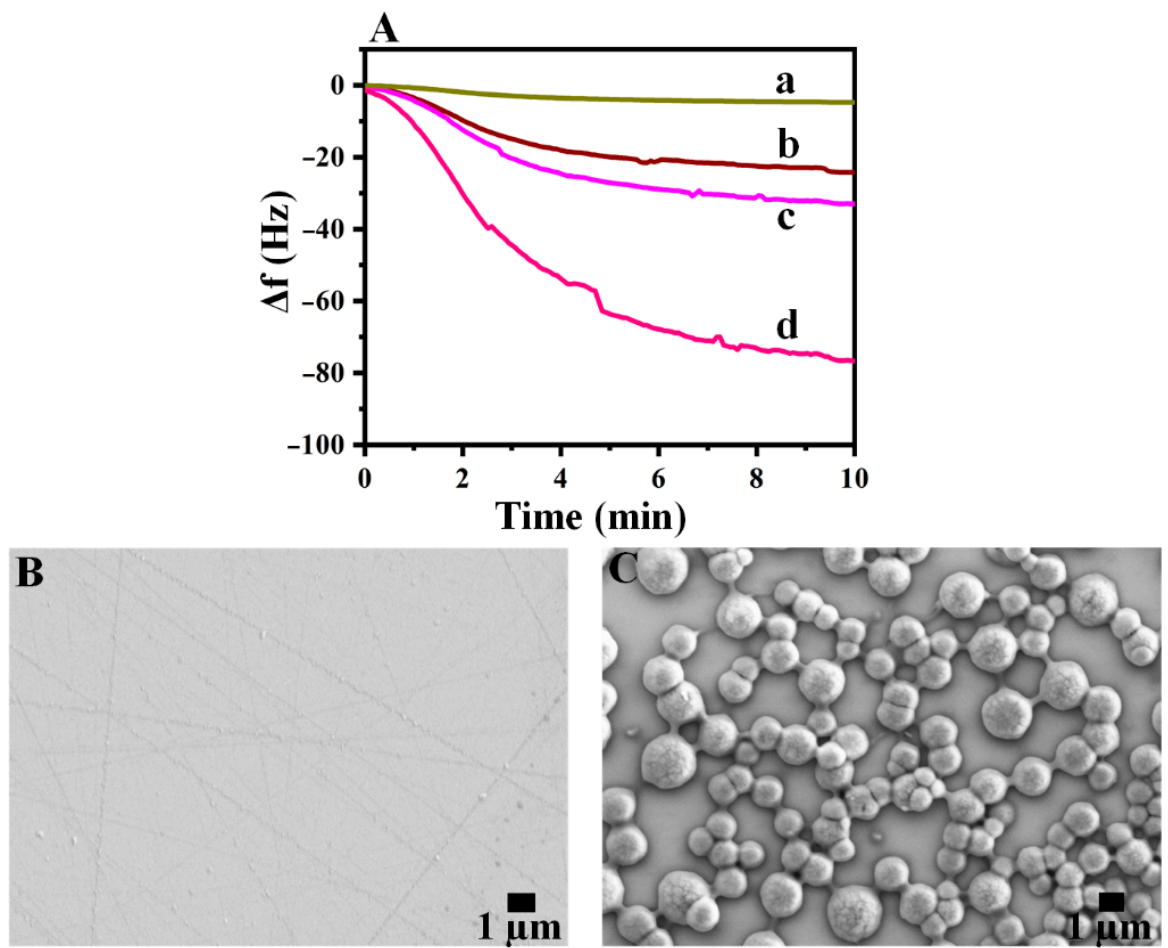

Figure 4. QCM responses (A) of bare electrode (a), MPA-treated electrode a (b), NHS/EDC-treated electrode $B(c)$, and $A b_{1}$-functionalized electrode $C(d)$; SEM images of delay line before $(B)$ and after immobilization of $\mathrm{Ab}_{1}(\mathbf{C})$.

SEM images were also used to verify the immobilization of the $A b_{1}$ on the delay line of the SAW surface. Figure 4C clearly shows the added thin layer of SAM on the SAW surface compared to the blank control in Figure 4B. These results are in agreement with previous reports [37]. The successful formation of SAM was confirmed further by measuring the contact angle of water droplets on the delay line of the SAW surface (Figure 5). As shown in Figure 5B, the contact angle was reduced from $79^{\circ}$ to $26^{\circ}$ after the formation of SAM.
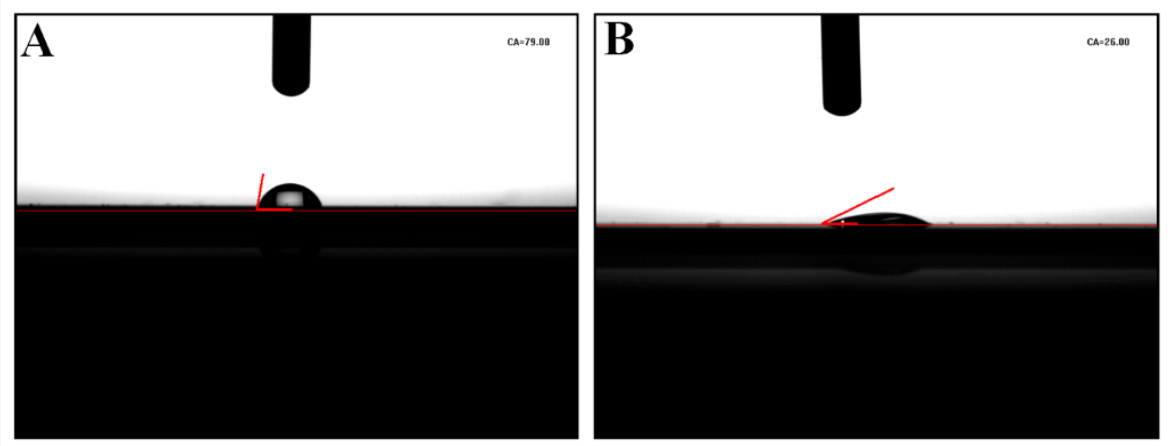

Figure 5. Contact angle of delay line before (A) and after immobilization of $\mathrm{Ab}_{1}(\mathbf{B})$.

The contact angles were drastically reduced after the formation of the SAM bioreceptor because of the adsorption of hydrophilic antibody molecules. The adsorbed polar biological molecules attract water molecules, resulting in a reduced contact angle after the formation of SAM. These results demonstrate the successful capture of $A b_{1}$ on the delay line of the SAW surface, as anticipated.

Optical microscopy images were further used to verify the immobilization of $A b_{1}$ on the delay line of the SAW surface. As shown in Figure S3Ab, the SAM-coated delay line distinctly shows the captured antibody molecules, which are absent from the blank control group. The capture of antibody molecules on the delay line was further confirmed using 
FITC-labeled primary antibody $\left(\mathrm{Ab}_{1}\right.$-FITC). As presented in Figure $\mathrm{S} 3 \mathrm{Bb}$, the fluorescent effect was observed only after the formation of SAM, indicating the successful capture of antibodies on the SAW surface, whereas the blank control remained dark, suggesting that no antibody was captured.

\subsection{Real-Time Detection Studies with SAW Immunosensor}

The typical response-time curve of the SAW immunosensor is presented in Figure 6A. At first, PBS was pumped through the chamber until stabilization of the center frequency baseline. Then, the AFP antigen mixed with $\mathrm{MoS}_{2} @ \mathrm{Cu}_{2} \mathrm{O}-\mathrm{Au}-\mathrm{Ab} \mathrm{b}_{2}$ conjugate was allowed to selectively bind with the specific antibodies in the flow cell, causing a large shift in the center frequency. The signals were amplified further, as the gold staining solution was introduced on the sensor surface, inducing gold deposition onto the captured AuNPs. The real-time detection curve indicates the successful binding of target AFP with specific antibodies and subsequent mass enhancement by gold staining. The frequency shift observed upon injection of AFP solution incubated with $\mathrm{Ab}_{2}$ (without conjugation with $\mathrm{MoS}_{2} @ \mathrm{Cu}_{2} \mathrm{O}-\mathrm{Au}$ nanoparticle) is shown in Figure S4.
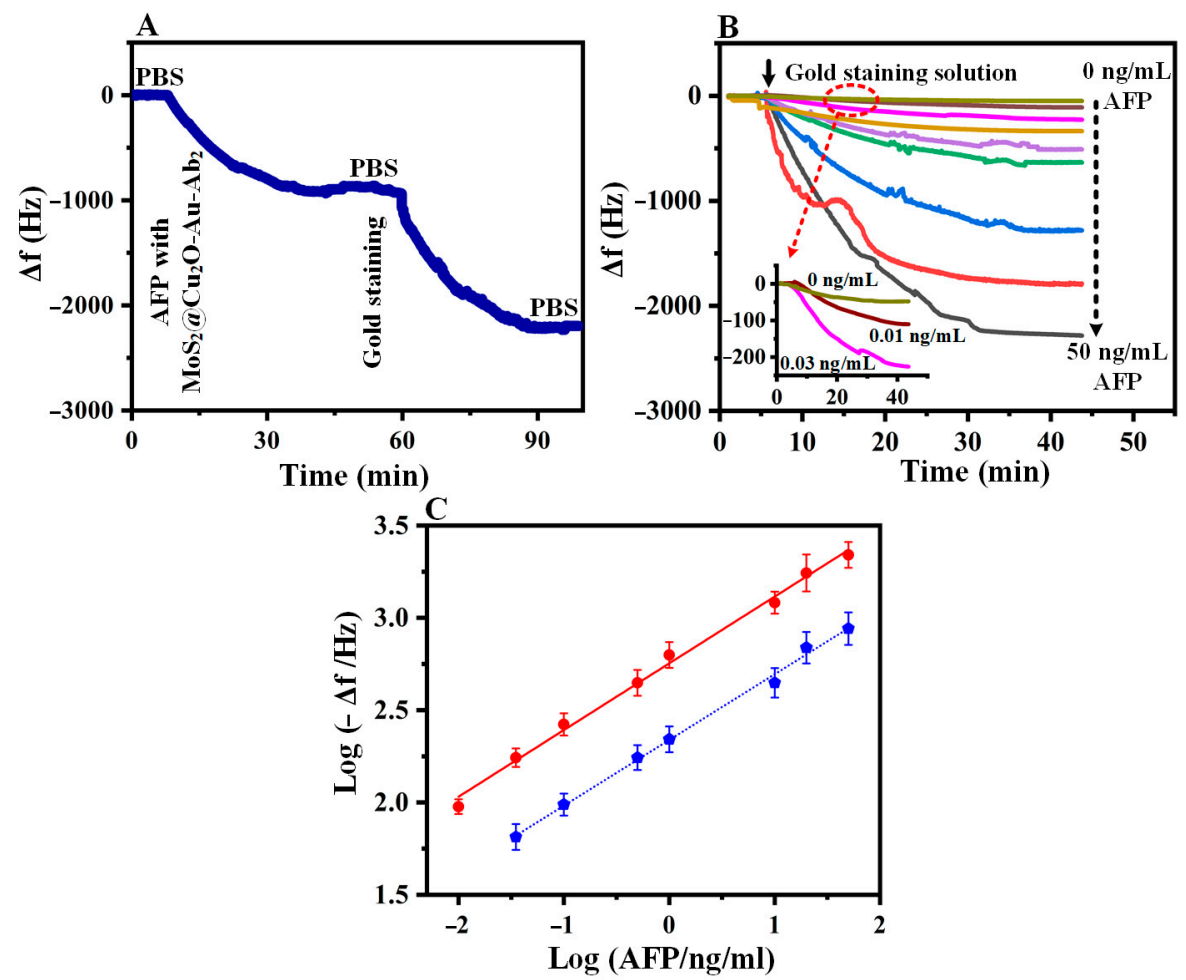

Figure 6. Real-time detection of AFP (A); frequency shifts observed upon injection of gold staining solution (after the injection of AFP solution mixed with $\mathrm{MoS}_{2} @ \mathrm{Cu}_{2} \mathrm{O}-\mathrm{Au}-\mathrm{Ab}_{2}$ conjugates) at varying concentrations from top to bottom in the order of $0,0.01,0.03,0.1,0.5,1.0,10,20$, and $50 \mathrm{ng} / \mathrm{mL}$ of AFP. The inset shows the magnification of the curve for $0,0.01$, and $0.03 \mathrm{ng} / \mathrm{mL}$ concentrations of AFP (B); frequency shifts observed as a function of AFP concentration with (solid line) and without gold staining (dotted line) on a log-log coordinate (C).

\subsection{Quantification of AFP}

To investigate the sensitivity of sandwich-type SAW immunosensor, various concentrations of AFP ranging from 0.01 to $50 \mathrm{ng} / \mathrm{mL}$ were tested and exposed to respective concentrations of gold staining solution. The real-time frequency shifts of the gold staining at different concentrations of AFP are presented in Figure 6B.

The center frequency shifts at saturation with different concentrations of AFP were extracted from real-time curves (Figure 6B) and normalized to fit into one plot (Figure 6C). In this graph, the center frequency value for each concentration is blank (without 
AFP) subtracted. In double logarithmic coordinates, a linear relationship between the center frequency shift and AFP concentration is obtained, with a correlation coefficient of 0.9942 (Figure 6C, solid line). The limit of detection (LOD) was estimated at $5.5 \mathrm{pg} / \mathrm{mL}$ for AFP with gold staining, calculated as the blank frequency shift by PBS $+3 \times$ noise [38] The LOD of the present immunosensor was significantly better than various piezoelectric immunosensors reported for the detection of AFP [39-41].

The analytical properties of the immunosensor were also tested without gold staining. A linear dependence was observed between the center frequency shift and AFP concentration ranging from 0.03 to $50 \mathrm{ng} / \mathrm{mL}$ on a $\log$-log coordinate with the correlation coefficient of 0.9958 . The LOD was estimated at $25 \mathrm{pg} / \mathrm{mL}$ for AFP in the absence of gold staining (Figure 6C, dotted line).

The excellent performance of the LSAW immunosensor might be attributed to two factors. First, $\mathrm{MoS}_{2} @ \mathrm{Cu}_{2} \mathrm{O}-\mathrm{Au}$ nanoparticles with high specific surface area and great biocompatibility not only increased the number of captured $\mathrm{Ab}_{2}$ but also magnified the mass loading on the sensor surface, resulting in high sensitivity even without gold staining. Similarly, gold staining as a signal amplification strategy further improved the sensitivity of immunosensor, resulting in an extremely low LOD for AFP.

\subsection{Immunosensor Selectivity}

The selectivity of the immunosensor has been evaluated for its vital role in examining biological fluids in situ without separation. The selectivity analysis was conducted by testing AFP and other interfering substances, such as the carcinoembryonic antigen (CEA), tryptophan, prostate-specific antigen (PSA), and BSA, each at a concentration of $10 \mathrm{ng} / \mathrm{mL}$. As shown in Figure 7A, the immunosensor did not exhibit any considerable affinity for the nonspecific analytes. A large frequency shift was observed only for the target AFP, while no significant frequency shift was detected corresponding to any nonspecific targets, indicating an acceptable selectivity of the developed immunosensor.
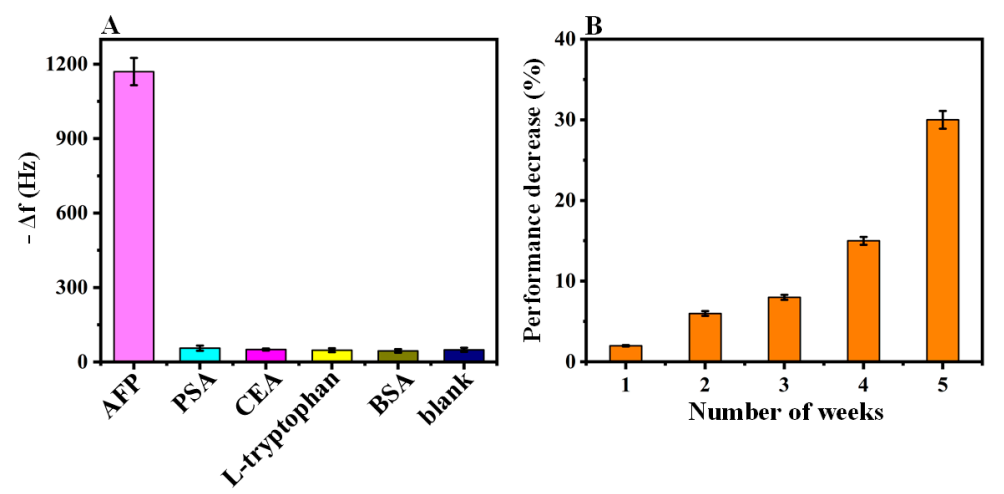

Figure 7. Comparison of gold staining amplified responses of the SAW immunosensor for AFP with nonspecific targets: concentrations of analytes were $10 \mathrm{ng} / \mathrm{mL}$ AFP, $10 \mathrm{ng} / \mathrm{mL}$ PSA, $10 \mathrm{ng} / \mathrm{mL}$ CEA, $10 \mathrm{ng} / \mathrm{mL}$ L-tryptophan, $10 \mathrm{ng} / \mathrm{mL}$ BSA, and $0 \mathrm{ng} / \mathrm{mL}$ AFP. (A) Storage stability of the SAW immunosensor at $4{ }^{\circ} \mathrm{C}$. Error bars show the mean \pm SD of three measurements $(B)$.

\subsection{Detection of AFP in Biological Fluids}

To evaluate the practical applicability of the proposed immunosensor, the results of APF detection in human serum and saliva samples were used as an effective analysis base. First, serum and saliva samples were diluted with PBS (2.5 fold); then, a standard concentration of AFP was added to each sample. Subsequently, the spiked samples were tested by the LSAW immunosensor, and the results are listed in Table 1. The obtained recovery values are in the satisfactory range of $95-108 \%$. 
Table 1. Detection of AFP in human saliva and serum samples.

\begin{tabular}{cccc}
\hline Sample & $\begin{array}{c}\text { Added } \\
(\mathbf{n g} / \mathbf{m L})\end{array}$ & $\begin{array}{c}\text { Found } \\
\mathbf{( n g / m L )}\end{array}$ & $\begin{array}{c}\text { Recovery (\%) } \\
\boldsymbol{n}=\mathbf{3}\end{array}$ \\
\hline Human serum & 0.50 & $0.53( \pm 0.03)$ & 106 \\
& 2.0 & $2.17( \pm 0.13)$ & 108 \\
Human saliva & 5.0 & $5.11( \pm 0.45)$ & 102 \\
& 0.5 & $0.47( \pm 0.02)$ & 94 \\
& 2.0 & $2.07( \pm 0.15)$ & 103 \\
\hline
\end{tabular}

Moreover, the commercially available ELISA method was employed as a reference method to validate the LSAW immunosensor. The data show good agreement between the two methods with high accuracy (Table 2). These results suggest that the proposed immunosensor is reliable for the detection of AFP in complex biological fluids.

Table 2. Comparison of the ELISA method for detection of human serum and saliva samples.

\begin{tabular}{ccc}
\hline Sample & $\begin{array}{c}\text { Elisa } \\
(\mathbf{n g} / \mathbf{m L})\end{array}$ & $\begin{array}{c}\text { Proposed Method } \\
(\mathbf{n g} / \mathbf{m L})\end{array}$ \\
\hline Human serum & $0.47( \pm 0.01)$ & $0.53( \pm 0.03)$ \\
& $2.13( \pm 0.17)$ & $2.09( \pm 0.12)$ \\
Human saliva & $5.42( \pm 0.37)$ & $5.25( \pm 0.47)$ \\
& $0.52( \pm 0.04)$ & $0.49( \pm 0.02)$ \\
& $2.19( \pm 0.12)$ & $2.18( \pm 0.14)$ \\
& $5.38( \pm 0.40)$ & $4.69( \pm 0.30)$ \\
\hline
\end{tabular}

The analytical properties of the LSAW immunosensor have been compared with previous reports in terms of their detection of AFP, and the results are summarized in Table S1. The LOD of the LSAW immunosensor was either comparable or superior to other detection methods, and our assay worked efficiently for different kinds of biological fluids, a factor not addressed in most of the reported methods in terms of AFP detection.

The LSAW immunosensor not only quantitatively detects the concentration of AFP but also monitors the capture of AFP by its specific antibodies in real time. Real-time detection provides information about the dynamics of antibody-antigen interaction and may facilitate real-time drug testing technology.

Moreover, the immunosensor operates under a continuous flow mode, making it particularly suitable for the direct detection of tumor markers in clinical samples, eliminating the need for pretreatment of clinical samples. This enables rapid analysis of clinical samples with a considerable reduction in the assay cost.

\subsection{Long-Term Stability}

Long-term stability of the LSAW immunosensor was tested for 5 weeks. The fabricated immunosensor was stored at $4{ }^{\circ} \mathrm{C}$ and tested for $50 \mathrm{ng} / \mathrm{mL}$ of AFP intermittently every week. According to Figure 7B, the center frequency response was about $70 \%$ of the initial value after 5 weeks, confirming excellent long-term storage stability of the SAW immunosensor.

\section{Conclusions}

We developed an ultrasensitive, sandwich-type leaky surface acoustic wave (LSAW) immunosensor based on coral $\mathrm{MoS}_{2} @ \mathrm{Cu}_{2} \mathrm{O}-\mathrm{Au}$ nanoparticles and subsequent gold staining for the real-time detection of alpha-fetoprotein (AFP) in biological fluids. A markedly enhanced sensitivity of the immunosensor was achieved by labeling the secondary antibodies with $\mathrm{MoS}_{2} @ \mathrm{Cu}_{2} \mathrm{O}-\mathrm{Au}$ nanoparticles. The detection sensitivity was increased further by employing gold staining as a signal amplification strategy. The proposed immunosensor exhibited long-term stability and satisfactory selectivity with an ultralow detection limit 
for AFP. These merits make our LSAW sensing platform prospective as an impressive novel method for ultrasensitive detection of AFP in clinical applications.

Supplementary Materials: The following are available online at https://www.mdpi.com/article/ 10.3390/chemosensors9110311/s1, Figure S1: Elemental mapping of $\mathrm{MoS}_{2} @ \mathrm{Cu}_{2} \mathrm{O}-\mathrm{Au}$, Figure S2: EDX spectra of $\mathrm{MoS}_{2} @ \mathrm{Cu}_{2} \mathrm{O}-\mathrm{Au}$, Figure S3: Optical microscopic images of the delay line before and after immobilization of $\mathrm{Ab}_{1}$ and FITC-Ab $\mathrm{b}_{1}$, Figure S4: Frequency shift observed upon injection of AFP solution incubated with $\mathrm{Ab}_{2}$, Table S1: Comparison of other methods for detection of AFP with SAW based immunosensor.

Author Contributions: Conceptualization, S.R. (Sana Rauf), H.I.A.Q. and J.L.; methodology, C.F., R.T. and S.R. (Sajid Rauf); validation, L.Y., H.L., Y.F.; formal analysis, J.L., S.R. (Sajid Rauf), R.T.; investigation, S.R. (Sana Rauf), R.T.; resources, J.L. and R.T.; data curation, S.R. (Sana Rauf); writingoriginal draft preparation, S.R. (Sana Rauf), R.T., C.F. and J.L.; writing—review and editing, S.R. (Sana Rauf), R.T. and J.L.; visualization, R.T. and J.L.; supervision, R.T. and J.L.; project administration, J.L.; funding acquisition, R.T. and J.L. All authors have read and agreed to the published version of the manuscript.

Funding: This work was financially supported by the Key Research and Development Program of Guangdong Province (Grant No.: 2020B0101040002), Special Projects in Key Fields of Colleges in Guangdong Province (2020ZDZX2097), Research Project in Fundamental and Application Fields of Guangdong Province (2020A1515110561), Guangdong Basic and Applied Basic Research Foundation (2019A1515111199), and Shenzhen Science \& Technology Project (Grant No. JCYJ20180507182106754, JCYJ20180507182439574, RCBS20200714114918249, GJHZ20200073109583010), the Engineering and Physical Sciences Research Council of UK (EPSRC EP/P018998/1), International Exchange Grant (IEC/NSFC/201078) through Royal Society and the National Natural Science Foundation of China, and EPSRC NetworkPlus in Digitalised Surface.

Institutional Review Board Statement: The study was conducted according to the guidelines of the Declaration of Helsinki, and approved by the Institutional Review Board.

Informed Consent Statement: Informed consent was obtained from all subjects involved in the study.

Data Availability Statement: The data presented in this study are available on request from the corresponding author.

Conflicts of Interest: The authors declare no conflict of interest.

\section{References}

1. Torre, L.A.; Bray, F.; Siegel, R.L.; Ferlay, J.; Lortet-Tieulent, J.; Jemal, A. Global cancer statistics, 2012. CA Cancer J. Clin. 2015, 65, 87-108. [CrossRef] [PubMed]

2. Wright, L.M.; Kreikemeier, J.T.; Fimmel, C.J. A concise review of serum markers for hepatocellular cancer. Cancer Detect. Prev. 2007, 31, 35-44. [CrossRef]

3. Gong, X.; Yan, H.; Yang, J.; Wu, Y.; Zhang, J.; Yao, Y.; Liu, P.; Wang, H.; Hu, Z.; Chang, J. High-performance fluorescence-encoded magnetic microbeads as microfluidic protein chip supports for AFP detection. Anal. Chim. Acta 2016, 939, 84-92. [CrossRef]

4. Wei, Y.; Li, Y.; Li, N.; Zhang, Y.; Yan, T.; Ma, H.; Wei, Q. Sandwich-type electrochemical immunosensor for the detection of AFP based on Pd octahedral and APTES-M-CeO ${ }_{2}$-GS as signal labels. Biosens. Bioelectron. 2016, 79, 482-487.

5. Wang, Y.; Zhao, G.; Wang, H.; Cao, W.; Du, B.; Wei, Q. Sandwich-type electrochemical immunoassay based on $\mathrm{Co}_{3} \mathrm{O}_{4} @ \mathrm{MnO}_{2-}$ thionine and pseudo-ELISA method toward sensitive detection of alpha fetoprotein. Biosens. Bioelectron. 2018, 106, 179-185. [CrossRef]

6. Shi, Y.; Yang, M.; Liu, L.; Pang, Y.; Long, Y.; Zheng, H. GTP as a peroxidase-mimic to mediate enzymatic cascade reaction for alkaline phosphatase detection and alkaline phosphatase-linked immunoassay. Sens. Actuators B Chem. 2018, 275, 43-49. [CrossRef]

7. Wang, C.; Wang, C.; Jin, D.; Yu, Y.; Yang, F.; Zhang, Y.; Yao, Q.; Zhang, G.-J. AuNP-Amplified surface acoustic wave sensor for the quantification of exosomes. ACS Sens. 2020, 5, 362-369. [CrossRef]

8. Jandas, P.J.; Luo, J.; Quan, A.; Qiu, C.; Cao, W.; Fu, C.; Fu, Y.Q. Highly selective and label-free Love-mode surface acoustic wave biosensor for carcinoembryonic antigen detection using a self-assembled monolayer bioreceptor. Appl. Surf. Sci. 2020, 518, 146061. [CrossRef]

9. Xu, Z.; Yuan, Y.J. Implementation of guiding layers of surface acoustic wave devices: A review. Biosens. Bioelectron. 2018, 99, 500-512. [PubMed] 
10. Matatagui, D.; Fontecha, J.L.; Fernández, M.J.; Gràcia, I.; Cané, C.; Santos, J.P.; Horrillo, M.C. Love-wave sensors combined with microfluidics for fast detection of biological warfare agents. Sensors 2014, 14, 12658-12669. [CrossRef]

11. Neves, M.A.D.; Blaszykowski, C.; Bokhari, S.; Thompson, M. Ultra-high frequency piezoelectric aptasensor for the label-free detection of cocaine. Biosens. Bioelectron. 2015, 72, 383-392. [CrossRef] [PubMed]

12. Gammoudi, I.; Blanc, L.; Moroté, F.; Grauby-Heywang, C.; Boissière, C.; Kalfat, R.; Rebière, D.; Cohen-Bouhacina, T.; Dejous, C. High sensitive mesoporous $\mathrm{TiO}_{2}$-coated love wave device for heavy metal detection. Biosens. Bioelectron. 2014, 57, 162-170. [CrossRef]

13. Rana, L.; Gupta, R.; Tomar, M.; Gupta, V. Highly sensitive Love wave acoustic biosensor for uric acid. Sens. Actuators B Chem. 2018, 261, 169-177. [CrossRef]

14. Bröker, P.; Lücke, K.; Perpeet, M.; Gronewold, T.M.A. A nanostructured SAW chip-based biosensor detecting cancer cells. Sens. Actuators B Chem. 2012, 165, 1-6. [CrossRef]

15. Kong, H.; Li, C.; Guo, Z.; Zhang, W.; Yao, J.; Zhu, H.; Yan, R.; Wang, L.; Li, J.; Wei, W.; et al. Sensitivity improved with Parylene-C passivized on Lamb wave sensor for aPTT measurement through monitoring whole blood reaction. Sens. Actuators B Chem. 2019, 285, 479-486. [CrossRef]

16. Arshak, K.; Moore, E.; Lyons, G.M.; Harris, J.; Clifford, S. A review of gas sensors employed in electronic nose applications. Sens. Rev. 2004, 24, 181-198. [CrossRef]

17. Ten, S.T.; Hashim, U.; Gopinath, S.C.B.; Liu, W.W.; Foo, K.L.; Sam, S.T.; Rahman, S.F.A.; Voon, C.H.; Nordin, A.N. Highly sensitive escherichia coli shear horizontal surface acoustic wave biosensor with silicon dioxide nanostructures. Biosens. Bioelectron. 2017, 93, 146-154. [CrossRef]

18. Belovickis, J.; Rimeika, R.; Čiplys, D. Acousto-optic interaction with leaky surface acoustic waves in $\mathrm{Y}_{\text {-cut }} \mathrm{LiTaO}_{3} \mathrm{crystals}$ Ultrasonics 2012, 52, 593-597. [CrossRef] [PubMed]

19. Meng, L.; Cai, F.; Zhang, Z.; Niu, L.; Jin, Q.; Yan, F.; Wu, J.; Wang, Z.; Zheng, H. Transportation of single cell and microbubbles by phase-shift introduced to standing leaky surface acoustic waves. Biomicrofluidics 2011, 5, 044104. [CrossRef]

20. Chang, K.; Wang, F.; Ding, Y.; Pan, F.; Li, F.; Jia, S.; Lu, W.; Deng, S.; Shi, J.; Chen, M. Development and validation of a novel leaky surface acoustic wave immunosensor array for label-free and high-sensitive detection of cyclosporin A in whole-blood samples. Biosens. Bioelectron. 2014, 54, 151-157. [CrossRef]

21. Chang, K.; Pi, Y.; Lu, W.; Wang, F.; Pan, F.; Li, F.; Jia, S.; Shi, J.; Deng, S.; Chen, M. Label-free and high-sensitive detection of human breast cancer cells by aptamer-based leaky surface acoustic wave biosensor array. Biosens. Bioelectron. 2014, 60, 318-324. [CrossRef] [PubMed]

22. Xu, Q.; Chang, K.; Lu, W.; Chen, W.; Ding, Y.; Jia, S.; Zhang, K.; Li, F.; Shi, J.; Cao, L.; et al. Detection of single-nucleotide polymorphisms with novel leaky surface acoustic wave biosensors, DNA ligation and enzymatic signal amplification. Biosens. Bioelectron. 2012, 33, 274-278. [CrossRef]

23. Zhang, L.; Wang, Y.; Chen, M.; Luo, Y.; Deng, K.; Chen, D.; Fu, W. A new system for the amplification of biological signals: RecA and complimentary single strand DNA probes on a leaky surface acoustic wave biosensor. Biosens. Bioelectron. 2014, 60, 259-264. [CrossRef]

24. Wang, Y.; Chen, M.; Zhang, L.; Ding, Y.; Luo, Y.; Xu, Q.; Shi, J.; Cao, L.; Fu, W. Rapid detection of human papilloma virus using a novel leaky surface acoustic wave peptide nucleic acid biosensor. Biosens. Bioelectron. 2009, 24, 3455-3460. [CrossRef] [PubMed]

25. Zhang, F.; Li, S.; Cao, K.; Wang, P.; Su, Y.; Zhu, X.; Wan, Y. A microfluidic love-wave biosensing device for PSA detection based on an aptamer beacon probe. Sensors 2015, 15, 13839-13850. [CrossRef] [PubMed]

26. Li, S.; Wan, Y.; Su, Y.; Fan, C.; Bhethanabotla, V.R. Gold nanoparticle-based low limit of detection Love wave biosensor for carcinoembryonic antigens. Biosens. Bioelectron. 2017, 95, 48-54. [CrossRef]

27. Chi, L.; Xu, C.; Li, S.; Wang, X.; Tang, D.; Xue, F. In Situ amplified QCM immunoassay for carcinoembryonic antigen with colorectal cancer using horseradish peroxidase nanospheres and enzymatic biocatalytic precipitation. Analyst 2020, 145, 6111-6118. [CrossRef]

28. Atar, N.; Yola, M.L. A novel QCM immunosensor development based on gold nanoparticles functionalized sulfur-doped graphene quantum dot and h-ZnS-CdS NC for Interleukin-6 detection. Anal. Chim. Acta 2021, 1148, 338202. [CrossRef]

29. Li, F.; Li, Y.; Feng, J.; Gao, Z.; Lv, H.; Ren, X.; Wei, Q. Facile synthesis of $\mathrm{MoS}_{2} @ \mathrm{Cu}_{2} \mathrm{O}-\mathrm{Pt}$ nanohybrid as enzyme-mimetic label for the detection of the Hepatitis B surface antigen. Biosens. Bioelectron. 2018, 100, 512-518. [CrossRef]

30. Zhao, X.; Li, Y.; Guo, Y.; Chen, Y.; Su, Z.; Zhang, P. Coral-Like $\mathrm{MoS}_{2} / \mathrm{Cu}_{2} \mathrm{O}$ Porous Nanohybrid with Dual-Electrocatalyst Performances. Adv. Mater. Interfaces 2016, 3, 1600658. [CrossRef]

31. Zou, L.; Tian, Y.; Zhang, X.; Fang, J.; Hu, N.; Wang, P. A competitive love wave immunosensor for detection of okadaic acid based on immunogold staining method. Sens. Actuators B Chem. 2017, 238, 1173-1180. [CrossRef]

32. Lee, J.; Lee, Y.; Park, J.-Y.; Seo, H.; Lee, T.; Lee, W.; Kim, S.K.; Hahn, Y.K.; Jung, J.Y.; Kim, S.; et al. Sensitive and reproducible detection of cardiac troponin I in human plasma using a surface acoustic wave immunosensor. Sens. Actuators B Chem. 2013, 178, 19-25. [CrossRef]

33. Lee, J.; Choi, Y.-S.; Lee, Y.; Lee, H.J.; Lee, J.N.; Kim, S.K.; Han, K.Y.; Cho, E.C.; Park, J.C.; Lee, S.S. Sensitive and Simultaneous Detection of Cardiac Markers in Human Serum Using Surface Acoustic Wave Immunosensor. Anal. Chem. 2011, 83, 8629-8635. [CrossRef] [PubMed] 
34. Kwak, J.; Lee, S.S. Highly sensitive piezoelectric immunosensors employing signal amplification with gold nanoparticles. Nanotechnology 2019, 30, 445502. [CrossRef]

35. Kimling, J.; Maier, M.; Okenve, B.; Kotaidis, V.; Ballot, H.; Plech, A. Turkevich method for gold nanoparticle synthesis revisited. J. Phys. Chem. B 2006, 110, 15700-15707. [CrossRef]

36. Bain, C.D.; Troughton, E.B.; Tao, Y.T.; Evall, J.; Whitesides, G.M.; Nuzzo, R.G. Formation of monolayer films by the spontaneous assembly of organic thiols from solution onto gold. J. Am. Chem. Soc. 1989, 111, 321-335. [CrossRef]

37. Ding, P.; Liu, R.; Liu, S.; Mao, X.; Hu, R.; Li, G. Reusable gold nanoparticle enhanced QCM immunosensor for detecting C-reactive protein. Sens. Actuators B Chem. 2013, 188, 1277-1283. [CrossRef]

38. Long, G.L.; Winefordner, J.D. Limit of detection. A closer look at the IUPAC definition. Anal. Chem. 1983, 55, 712A-724A.

39. Tsai, W.-C.; Lin, I.C. Development of a piezoelectric immunosensor for the detection of alpha-fetoprotein. Sens. Actuators B Chem. 2005, 106, 455-460. [CrossRef]

40. Ding, Y.; Liu, J.; Wang, H.; Shen, G.; Yu, R. A piezoelectric immunosensor for the detection of $\alpha$-fetoprotein using an interface of gold/hydroxyapatite hybrid nanomaterial. Biomaterials 2007, 28, 2147-2154. [CrossRef]

41. Xu, T.; Miao, J.; Wang, Z.; Yu, L.; Li, C.M. Micro-piezoelectric immunoassay chip for simultaneous detection of Hepatitis B virus and $\alpha$-fetoprotein. Sens. Actuators B Chem. 2011, 151, 370-376. [CrossRef] 